\title{
Influence of Bearing Band on Flow Field of Projectile with Base Cavity
}

\author{
Yang $\mathrm{Ni}^{\mathrm{a}}{ }^{*}$ and Haibo Lu ${ }^{\mathrm{b}}$ \\ Nanjing Artillery Academy, Nanjing, 211132, China \\ atougaoy126@126.com, ${ }^{\mathrm{b}}$ Ihbboo@sohu.com
}

Keywords: Bearing band; Projectile with base cavity; Flow field; Numerical simulation

\begin{abstract}
The paper focuses on the influence of bearing band on the flow field and aerodynamic force of the projectile. Numerical model of projectile with and without bearing band are simulated under a supersonic flow condition. The flow field parameters and the aerodynamic drag coefficient of models were obtained. The numerical results indicate that the bearing band causes a detached bow shock in front of it and increases the aerodynamic drag of the projectile obviously. Along the surface of the projectile, the bearing band leads to flow separation, but reattached soon.
\end{abstract}

\section{Introduction}

The bearing band is the necessary configuration for the projectile which is used in rifle cannon to spin and self-stabilization [1]. The choise of the bearing band is an indispensable work for the projectile design $[2,3]$. Nowadays, the study on bearing band focuses on its engraving process [4-8]. But with the requirement of further range of fire and higher firing accuracy for the artillery, the effect of the bearing band on flow field and aerodynamic force of the projectile should be regarded with some care.

In the present study, the influence of the bearing band on the flow field and aerodynamic drag of the projectile is investigated numerically. The difference of the flow field between projectile with or without bearing band is compared for the further research.

\section{Numerical Method}

Governing Equation The $k$ - $\varepsilon$ turbulence model [9] and the axisymmetric Navier-Stokes equation [10] are used in the simulation. The $\mathrm{N}-\mathrm{S}$ equation is given by

$$
\frac{\partial U}{\partial t}+\frac{\partial E}{\partial x}+\frac{\partial F}{\partial r}+\frac{S}{r}=\frac{1}{\operatorname{Re}}\left(\frac{\partial E_{v}}{\partial x}+\frac{\partial F_{v}}{\partial r}+\frac{H}{r}\right)
$$

where $x$ is the flow direction, $r$ is the radial.

$$
U=\left[\begin{array}{c}
\rho \\
\rho u \\
\rho v \\
e
\end{array}\right], E=\left[\begin{array}{c}
\rho u \\
\rho u^{2}+p \\
\rho u v \\
u(e+p)
\end{array}\right], F=\left[\begin{array}{c}
\rho v \\
\rho u v \\
\rho v^{2}+p \\
v(e+p)
\end{array}\right], S=\left[\begin{array}{c}
\rho v \\
\rho u v \\
\rho v^{2} \\
v(e+p)
\end{array}\right], E_{v}=\left[\begin{array}{c}
0 \\
\tau_{x x} \\
\tau_{x r} \\
q_{x}
\end{array}\right], F_{v}=\left[\begin{array}{c}
0 \\
\tau_{r x} \\
\tau_{r r} \\
q_{r}
\end{array}\right], H=\left[\begin{array}{c}
0 \\
\tau_{r x} \\
\tau_{r r} \\
q_{r}
\end{array}\right]
$$

$\tau$ is the shearing stress, $q$ is the heat flux, $\rho$ is the density of the free stream, $u$ is the axial velocity of the free stream, $v$ is the radial velocity of the free stream, $T$ is the temperature of the free stream, $p$ is the pressure of the free stream, $e$ is the energy per unit mass fluid $\left(e=\rho\left[C_{v} T+\left(\mathrm{u}^{2}+\mathrm{v}^{2}\right) / 2\right]\right)$ of the free stream.

The convective term is approximated with the Van Leer splitting method [11]. The central difference method is used for the viscous terms. The LU-SSOR scheme is used for the time integration.

Grid and Boundary Conditions As shown in Figure 1, the body-fitted grid of the projectile is given. 


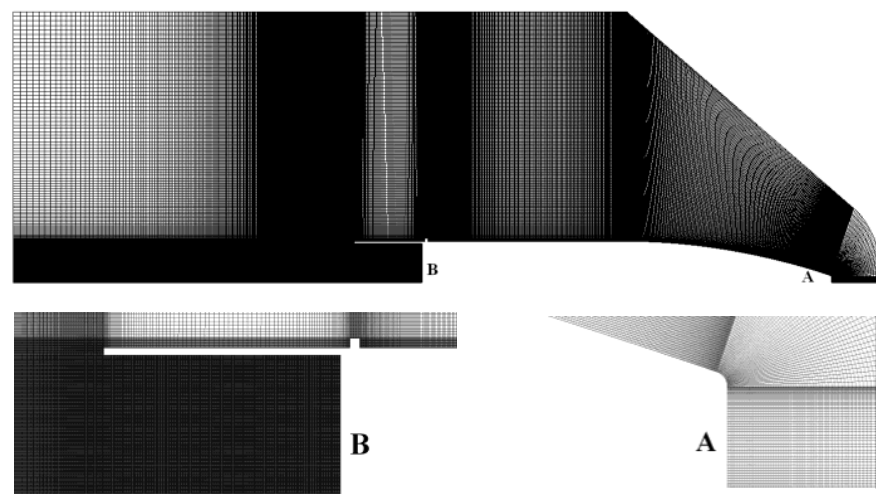

Figure 1. Grid of the simulation model

The flow conditions of the simulation are shown in Table 1 . The wall boundary condition is assumed to no-slip and adiabatic.

Table 1 Boundary conditions

\begin{tabular}{|c|c|c|}
\hline Free stream parameter & Unit & Value \\
\hline Mach Number $(M a)$ & ---- & 1.97 \\
\hline Pressure $\left(p_{\infty}\right)$ & $\mathrm{Pa}$ & 101325 \\
\hline Temperature $\left(T_{\infty}\right)$ & $\mathrm{K}$ & 300 \\
\hline
\end{tabular}

\section{Results and Discussion}

Flow Field The distributions of $M a$ contours and streamlines of the projectile with or without bearing band are shown in Fig. 2 and Fig. 3. As shown, there is a classical detached bow shock wave formed in front of projectiles. At the bottom of projectiles, there is a violent expansion wave and a large recirculation region is formed in the base cavity. The difference is, because of the existence of the bearing band, a bow shock in front of it is formed. And separation and reattachment occur on the boundary layer of the projectile. The bow shock in front of the bearing band reduces the velocity of the flow behind it, then, the expansion flow which is behind the bottom of the projectile is weakened. A local enlarged drawing (near the bearing band) of the $M a$-streamline distribution of the projectile with bearing band is given in Fig. 4. Along the surface of the projectile, the bearing band leads to flow separation, but reattached soon.

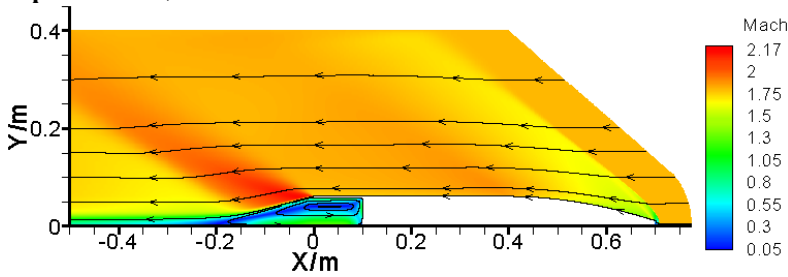

Figure 2. $M a$ (streamline) distribution (without bearing band)

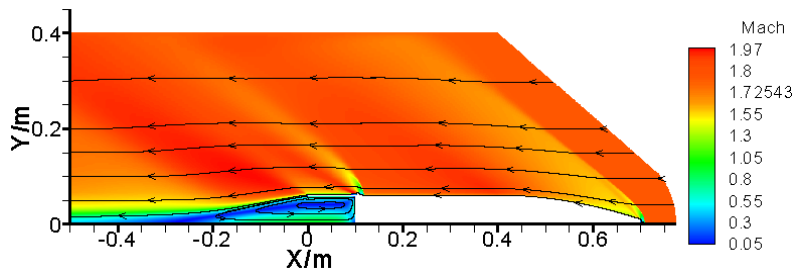

Figure 3. $M a$ (streamline) distribution (with bearing band)

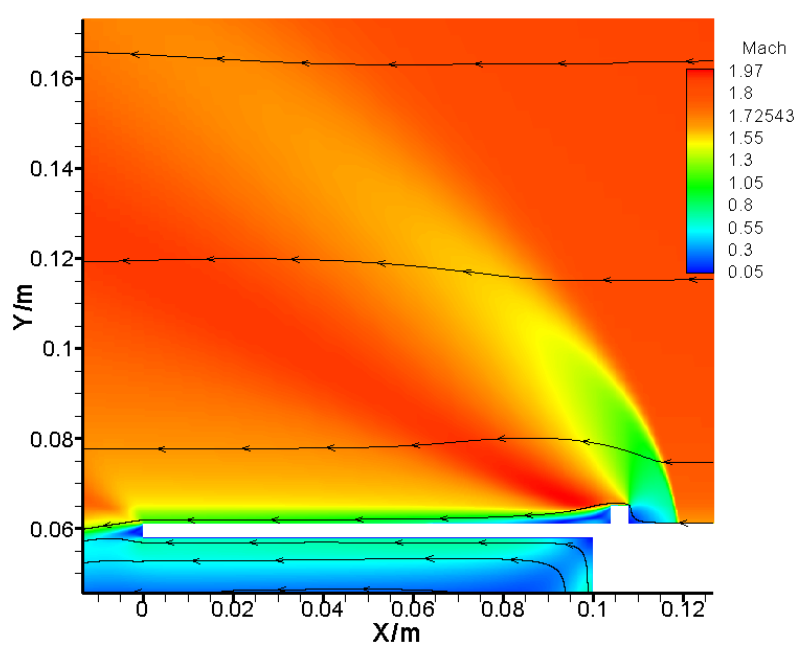

Figure 4. Local enlarged drawing of the $M a$-streamline distribution (with bearing band) 
As shown in Fig. 5 and Fig. 6, the distribution of temperature of the projectile with or without bearing band are given. The temperature maximum is located in the high temperature area which is formed inside the base cavity. The distributions of pressure of the projectile with or without bearing band are given in Fig. 7 and Fig. 8. The pressure maximum is located at the stagnation point.

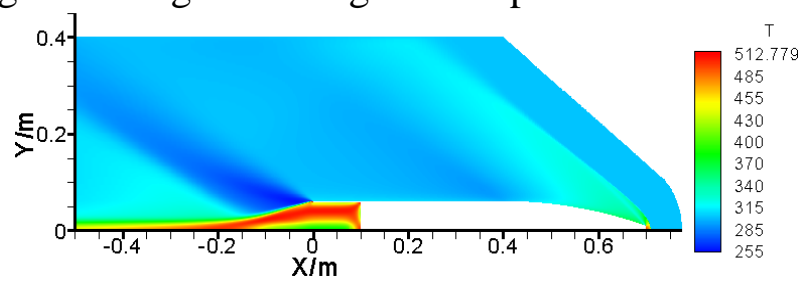

Figure 5. Temperature distribution (without bearing band)

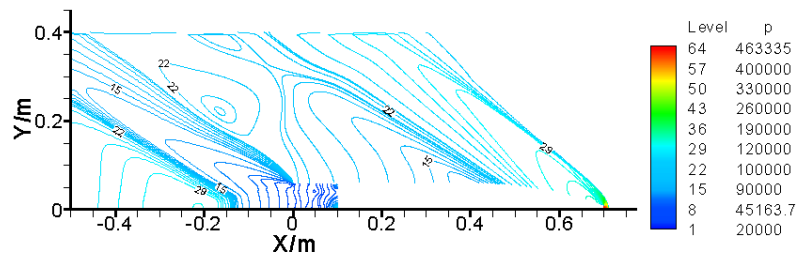

Figure 7. Pressure distribution (without bearing band)

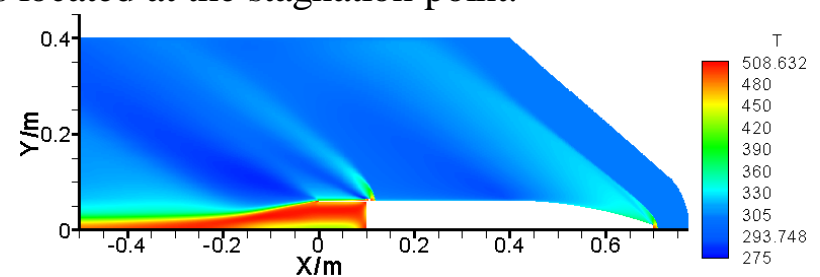

Figure 6. Temperature distribution (with bearing band)

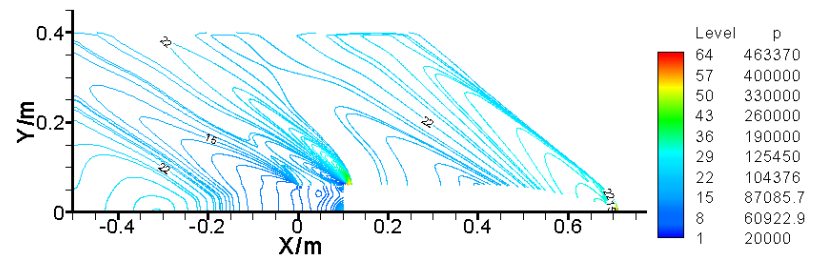

Figure 8. Pressure distribution (with bearing band)

Aerodynamic drag The drag coefficient $\left(C_{d}\right)$ of the projectile is given by:

$$
C_{d}=F_{d} /\left(\frac{1}{2} \rho u^{2} \cdot S_{r e f}\right)
$$

where $F_{d}$ is the aerodynamic drug, $S_{r e f}$ is the reference area (the cross section of the projectile) .

The aerodynamic drag coefficient of the projectile without bearing band is 0.3267 . The aerodynamic drag coefficient of the projectile with bearing band is 0.4783 . It is obviously that the bearing band increases the aerodynamic drag of the projectile.

\section{Conclusion}

Projectiles with and without bearing band were investigated numerically. The distribution of the flow field and the aerodynamic drag force of the projectile under a supersonic flow condition were obtained. The effect of the bearing band on the projectile flow field and the aerodynamic force was discussed.

Separation and reattachment occur on the boundary layer of the projectile by the existence of the bearing band. Along the surface of the projectile, the bearing band leads to flow separation, but reattached soon.

Bow shock is formed in front of the bearing band and the aerodynamic drag of the projectile is increased greatly by it.

\section{References}

[1] HE Zhiqiang, HUANG Shouren, LI Zaihong. Hand book for airborne automatic weapon design [M]. Beijing: National Defense Industry Press, 1991: 190-216. (in Chinese )

[2] Wei Huizhi, Zhu Songhe, Wang Donghui, Du Xinliang. Theory of Projectile design [M]. Beijing: National Defense Industry Press, 1985. (in Chinese )

[3] Zhao Wenyi. Projectile design principle. Beijing: Beijing Institute of Technology Press, 1988 (in Chinese ) 
[4] DING Chuanjun, ZHANG Xiangyan. Simulation Study of Bearing Band Engraving Process and Interior Ballistic Process Based on Thermo-mechanical Coupling FEA Model. Acta Armamentarii, 2015, 36 (12): 2254-2261. (in Chinese)

[5] FAN Lixia, HE Xiangyue. Finite element simulation and process analysis of projectile entering into barrel [J]. Acta Armamentarii, 2011, 32 (8): 963-968. (in Chinese)

[6] HU Huibin, CHEN Shuxiao, WANG Hongbo, CAO Lijan. Tribological Test and Failure Mechanism Analysis of Driving Band's Engraving Processunder. Fire Control \& Command Control, 2015, 40(12): 167-170. (in Chinese)

[7] MA Shuai, ZHANG Xiangyan, YOU Xiudong. Engraving Simulation Based on ANSYS/LS -DYNA. Machine Building \& Automation, 2014, 43(5): 92-98. (in Chinese)

[8] Sun H Y, Ma J S, Yao J J. Dynamic Analysis on the Rotating Band's Engraving Process[C]. Advanced Material Research, Trans Tech Publications, Switerland, 2010.

[9] W.Q. Tao, Numerical Heat Transfer, 2nd ed. Xi' an: Xi'an Jiaotong University Press, 2001 (in Chinese)

[10] X.S. Wu, The numerical investigation on flow field of projectile (with base bleed), Journal of ballistics, 4 (1992) 39-43. (in Chinese)

[11] X.D. Wang, J.J. Tan, X.H. Lin and Z.H. Tang, Research on parallel numerical simulation of N-S equations based on Van Leer+AUSM scheme, Journal of Astronautics, 31(2010) 986-992. (in Chinese) 